\title{
The Effect of Stress Ageing on the Properties of Shape Memory Alloys
}

A.D. Michael

Memory Metals Limited, 3 Penny Corner, Farthing Road, Ipswich, Suffolk IP1 5AP, England, U.K.

\begin{abstract}
The performance characteristics of shape memory alloys operating in an overtemperature shut-off valve at a temperature of $95^{\circ} \mathrm{C}$ for up to 2000 hours are presented. Alloys of NiTi, $\mathrm{Cu}-\mathrm{Al}-\mathrm{Ni}$ and $\mathrm{Cu}-\mathrm{Zn}-\mathrm{Al}$ have been characterised under these ageing conditions. The effect of altering the processing parameters, viz solution treatment temperature, quenching technique and training procedure were examined. All alloys show degradation of the memory behaviour but results are presented which demonstrate that improvements in degradation can arise by altering the solution treatment temperature and training procedure.
\end{abstract}

\section{BACKGROUND}

A potential client approached Memory Metals Limited with a request for incorporating a memory metal spring as an overtemperatire shut-off valve in his product. The client stipulated that the following parameters must apply.

- The operating temperature to be $95^{\circ} \mathrm{C}$ and the spring would be exposed to this temperature for periods of up to 350 hours.

- At $95^{\circ} \mathrm{C}$ the spring to deflect $6 \mathrm{~mm}$ and exert a force of $7 \mathrm{~N}$.

- A life cycle of 2000 hours at $95^{\circ} \mathrm{C}$.

- Cost would be an important criteria in the selection of memory metal for this application.

\section{INTRODUCTION}

There were three commercial alloys that could be considered for this application, viz NiTi, Cu-Al-Ni and $\mathrm{Cu}-\mathrm{Zn}-\mathrm{Al}$. For NiTi and $\mathrm{Cu}-\mathrm{Zn}-\mathrm{Al}$ the operating temperature of $95^{\circ} \mathrm{C}$ is close to the maximum operating temperature recommended for these alloys. Their preferred use at these temperatures is in single or low cycle applications because on cycling the transformation temperature tends to walk to higher temperatures [1]. However, $\mathrm{Cu}-\mathrm{Al}-\mathrm{Ni}$ memory alloys are known to have better thermal stability at this temperature [2]. Unfortunately, the mechanical processing characteristics of $\mathrm{Cu}-\mathrm{Al}-\mathrm{Ni}$ alloys do not compare as favourably as those of $\mathrm{Cu}-\mathrm{Zn}-\mathrm{Al}$ and are not so good as NiTi due to the presence of brittle $\gamma$ 
precipitates [3]. Also, Cu-Al-Ni alloys are not as widely commercially available as the other two memory alloys.

Although this background knowledge on the behaviour of memory alloys at $95^{\circ} \mathrm{C}$ was known, data on their ageing characteristics at this temperature for the conditions met in this application did not exist. Therefore, in order to select the memory alloy most suitable for this application, a test programme on the performance of these alloys proved necessary.

As the cost of the memory spring was to be an important parameter in the final selection of the alloy system, the test programme was set up so as to consider the effect of processing parameters on the ageing characteristics. The processing parameters examined were solution treatment temperature, quenching technique and training procedure.

For NiTi alloys a training cycle of 100 cycles is recommended for stabilising the memory characteristics particularly where cycle life is important [4]. However, for this application the ageing characteristics rather than the cycling behaviour at $95^{\circ} \mathrm{C}$ were more important and therefore fewer training cycles may have proved acceptable.

The standard training cycle for copper-based alloys to achieve stability and two way memory is 10 cycles through the transformation band. There have been reports $[5,6]$ that training techniques involving no cycling but ageing the memory alloy under stress (stabilised stress induced martensite training) results not only in two way memory without any training cycles but also in an improvement in the stability of the $A_{s}$ temperature on subsequent cycling [7].

A further technique for improving the stability of the $A_{s}$ temperature in copper-based alloys is by adjustment of the solution treatment temperature. This results in a duplex $\alpha \beta$ structure [8].

\section{EXPERIMENTAL}

The memory alloys required an $\mathrm{A}_{\mathrm{s}}$ temperature of 80 to $85^{\circ} \mathrm{C}$ in order to achieve the operating parameters of the product. In Table 1 the chemical composition of the memory alloys investigated are given.

Table 1 Alloy Compositions

\begin{tabular}{|c|c|c|c|c|c|c|}
\hline Alloy & $\% \mathrm{Ni}$ & $\% \mathrm{Ti}$ & $\% \mathrm{Cu}$ & $\% \mathrm{Zn}$ & $\% \mathrm{Al}$ & $\% \mathrm{Ni}$ \\
\hline 1 & 53.90 & 46.10 & - & - & - & - \\
\hline 2 & - & - & 81.80 & - & 13.50 & 4.70 \\
\hline 3 & - & - & 73.70 & 20.62 & 5.68 & - \\
\hline
\end{tabular}

To achieve the required $\mathrm{A}_{\mathrm{s}}$, the NiTi springs were heat treated at two different temperatures; the untrained springs were heat treated at $425^{\circ} \mathrm{C}$ and the springs to be given training cycles were heat treated at $500^{\circ} \mathrm{C}$. This is necessary since during the first few training cycles, the $A_{s}$ temperature shifts to lower temperatures and then stabilises.

The $\mathrm{Cu}-\mathrm{Zn}-\mathrm{Al}$ springs were given the following treatments.

SSMC19 Standard treatment. Solution treated at $800^{\circ} \mathrm{C}$, step quenched to $100^{\circ} \mathrm{C}$ and air cooled to room temperature. Trained by cycling between $20^{\circ} \mathrm{C}$ to $150^{\circ} \mathrm{C}$. 
SSM1 As SSMC19 but no cycling; spring compressed so that is was open to $30 \%$ of its fully open state and stress aged at $150^{\circ} \mathrm{C}$ for 30 minutes.

SSMC1 After step quenching to $150^{\circ} \mathrm{C}$, the spring was compressed to its coil bound state at $150^{\circ} \mathrm{C}$ and stress aged for 30 minutes.

AB5 As sample SSMC19 but solution treatment temperature $620^{\circ} \mathrm{C}$.

$\mathrm{Cu}-\mathrm{Al}-\mathrm{Ni}$ springs were heat treated at $800^{\circ} \mathrm{C}$, water quenched to room temperature and aged at $150^{\circ} \mathrm{C}$ for 1 hour. They were trained by cycling between $20^{\circ} \mathrm{C}$ and $150^{\circ} \mathrm{C}$

Springs were trained by cycling against a bias spring having a spring rate of $1.2 \mathrm{~N} / \mathrm{mm}$ with a preload of $0 \mathrm{~N}$ and $4 \mathrm{~N}$ for the copper-based alloys and the NiTi alloy, respectively. The NiTi spring required a preload of $4 \mathrm{~N}$ in order to return to its coilbound state on cooling to room temperature.

Using the same bias springs and preloads, the springs were aged at $95^{\circ} \mathrm{C}$ for 2000 hours in a water bath. At various time intervals upto 2000 hours, the springs were removed from the water bath and their deflection measured at $95^{\circ} \mathrm{C}$.

\section{RESULTS}

Figures 1 and 2 show the deflections of the test springs as a function of ageing time for the NiTi and copper-based alloys, respectively. For the NiTi alloy, the importance of the training cycles prior to ageing is clearly demonstrated; with no cycles there is a large reduction in deflection on ageing which is reduced as the number of training cycles increases.

Prior to ageing, all the copper-based alloys exhibited two way memory. The effect of stabilised stress induced martensite training results in a reduction in the initial deflection; the reduction being greater for the spring stress aged in its fully coil bound state.

It is well established that $\mathrm{Cu}-\mathrm{Al}-\mathrm{Ni}$ alloys exhibit better high temperature stability than $\mathrm{Cu}-\mathrm{Zn}-\mathrm{Al}$ alloys and this is borne out by the results presented in Figure 2.

Table 2 Degradation results for NiTi

\begin{tabular}{|c|c|}
\hline $\begin{array}{c}\text { Training } \\
\text { Cycles }\end{array}$ & $\begin{array}{c}\% \\
\text { Degradation }\end{array}$ \\
\hline 0 & 72.7 \\
\hline 25 & 46.5 \\
\hline 50 & 28.9 \\
\hline 100 & 22.9 \\
\hline
\end{tabular}

Table 3 Degradation results for copper-based alloys

\begin{tabular}{|c|c|c|}
\hline Alloy & Sample & $\begin{array}{c}\% \\
\text { Degradation }\end{array}$ \\
\hline Cu-Al-Ni & - & 23.7 \\
\hline Cu-Zn-Al & SSMC19 & 87.1 \\
\hline Cu-Zn-Al & SSM1 & 84.9 \\
\hline Cu-Zn-Al & SSMC1 & 75.5 \\
\hline Cu-Zn-Al & AB5 & 57.3 \\
\hline
\end{tabular}

In Tables 2 and 3 the \% reduction in deflection (ie. \% degradation) on ageing for 2000 hours is shown for the different alloys and different treatments. For the NiTi alloy, with increasing number of training cycles, the \% degradation decreases. The $\mathrm{Cu}-\mathrm{Al}-\mathrm{Ni}$ alloy shows less degradation than the $\mathrm{Cu}-\mathrm{Zn}-\mathrm{Al}$ alloy even after the modified thermal mechanical treatments. In fact, the $\mathrm{Cu}-\mathrm{Al}-\mathrm{Ni}$ alloy compares favourably with the NiTi alloy after 100 training cycles in that the \% degradation is similar. From Table 3, 
it would appear that ageing stabilised stress induced martensite trained material and a duplex structure of $\alpha \beta$ does improve the degradation characteristics of $\mathrm{Cu}-\mathrm{Zn}-\mathrm{Al}$ alloys. The most improvement being achieved in the duplex structure.

After the ageing tests at $95^{\circ} \mathrm{C}$ had been completed, all test springs were given one cycle upto $150^{\circ} \mathrm{C}$. Both the NiTi and $\mathrm{Cu}-\mathrm{Al}-\mathrm{Ni}$ springs recovered the degradation that had occurred on ageing at $95^{\circ} \mathrm{C}$. The $\mathrm{Cu}-\mathrm{Zn}-\mathrm{Al}$ springs showed no such recovery in their deflection behaviour.

\section{DISCUSSION}

The degradation characteristics of the three memory alloys under the conditions examined in this investigation show them to be different. In the case of NiTi and $\mathrm{Cu}-\mathrm{Al}-\mathrm{Ni}$ alloys, degradation is due to the upward movement of the transformation temperature to higher temperatures on ageing. For the NiTi alloy, as the degradation decreases with increasing number of training cycles, a more stable transformation temperature occurs thus resulting in a reduction in the degree of upward movement on ageing. However, for $\mathrm{Cu}-\mathrm{Zn}-\mathrm{Al}$ alloys, this upward movement appears not to occur and would indicate that the degradation arises due to structural changes taking place in the $\beta$ phase, either the ordering of the $\beta$ is affected or the bainite structure forms on ageing.

From the results presented both solution treatment temperature and training procedure affect the degradation of the $\mathrm{Cu}-\mathrm{Zn}-\mathrm{Al}$ alloy. Lowering the solution treatment temperature results in a duplex structure of $\alpha \beta$. An electron micrograph of the duplex structure is shown in Figure 3 which shows the form and distribution of the $\alpha$. Its appearance is blocky and is frequently but not exclusively associated with the $\beta$ grain boundaries. An example of such an $\alpha$ grain is marked at $A$. It would appear that the presence of the $\alpha$ modifies the change in the ordering of the $\beta$ or affects the rate of formation of the bainite. The presence of $\alpha$ in the $\beta$ results in the zinc and aluminium content of the $\beta$ phase increasing and therefore the chemical composition of the $\beta$ is altered. This would be expected to affect both the ordering of the $\beta$ and the formation of bainite. For this supposition to be correct, the slight improvement in degradation achieved after stabilised stress induced martensite training should arise from the same cause, ie. precipitates within the $\beta$. It has been reported [9] that this training technique results in the precipitation of the $\gamma$ phase; it is the strain fields associated with the $\gamma$ precipitates which gives rise to the stabilised stress induced martensite which produces two way memory without any thermal training cycles. In the electron micrograph (Figure 4) for sample SSM1, localised strain centres ( marked at A) evenly distributed in the $\beta$ were found and these are believed to be the $\gamma$ phase. However, in sample SSMC1 which showed a slight improvement in degradation compared with samples SSM1 and SSMC19, the presence of $y$ precipitates was not detected, but the presence of a tweed structure was found. The presence of $Y$ precipitate or the tweed structure was not detected in sample SSMC19 given the standard treatment, and therefore, it is concluded that their presence in the stabilised stress induced martensite trained samples affects the composition of the $\beta$ phase. If so, this supports the argument that it affects the ordering reaction or the formation of bainite.

The rate of formation of the $\gamma$ phase will depend upon a diffusion process. This is affected by the stress applied during stabilised stress induced martensitic training since in the spring given the standard treatment no $\gamma$ phase or tweed structure was detected. A quenching temperature of $150^{\circ} \mathrm{C}$ compared with $100^{\circ} \mathrm{C}$ will result in a lower vacancy concentration and this in turn will affect the diffusion rate and hence the formation of the $\gamma$ phase. Therefore, the difference in the structures for springs SSM1 and SSMC1 is due to the initial vacancy concentration prior to stabilised stress induced martensitic training.

\section{CONCLUSIONS}

This investigation has shown that three memory alloys, NiTi, Cu-Al-Ni and Cu-Zn-Al with an $\mathrm{A}_{\mathrm{s}}$ of 80 to $85^{\circ} \mathrm{C}$ degrade on ageing at $95^{\circ} \mathrm{C}$ for 2000 hours. In conjunction with this test programme, the client 
established from in-situ tests on the overtemperature shut-off valve with memory alloy springs that some degradation could be tolerated. Consequently, either the NiTi alloy after 100 training cycles or the $\mathrm{Cu}-\mathrm{Al}-\mathrm{Ni}$ alloy would be acceptable for this application. Unfortunately, both NiTi and $\mathrm{Cu}-\mathrm{Al}-\mathrm{Ni}$ alloys are expensive and with their difficulties in fabricating and processing springs, the resultant cost was not quite within the limits set by the client. This has resulted in the original volume estimates for fitting a memory alloy spring for this overtemperature shut-offf valve being reduced.

A spring made from $\mathrm{Cu}-\mathrm{Zn}-\mathrm{Al}$ would be more appropriate for this application because cost would not be a constraint due to the ease of fabricating and processing springs from this memory alloy. Whilst this investigation has shown that improvements in the degradation behaviour can be achieved by altering the solution treatment temperature, quenching technique and training procedure, the improvements are insufficient to enable a $\mathrm{Cu}-\mathrm{Zn}-\mathrm{Al}$ alloy to be used in this application.

\section{REFERENCES}

[1] Stoeckel D., Engineering Aspects of Shape Memory Alloys (Butterworth-Heinemann, London, 1990) pp. 283-294.

[2] Duerig T. W., Albrecht J. and Gessinger G. H., J. Metals 12 (1982) pp. 12-20.

[3] Sugimoto K., Kamei K. and Nakaniwa M., Engineering Aspects of Shape Memory Alloys

(Butterworth-Heinemann London, 1990) pp. 89-95.

[4] Miyazaki S., Engineering Aspects of Shape Memory Alloys (Butterworth-Heinemann, London, 1990) pp. 394-413.

[5] Guilemany J. M., Fernandez J.and Mellor B. G., Scripta Metall 24 (1990) pp. 1941-1945.

[6] Mellor B. G., Guilemany J. M. and Fernandez J., European Symposium on Martensitic

Transformation and Shape Memory Properties, (J. de Physique, suppl III, 1, 1991) pp. 457-462

[7] Mellor B. G. et al, Scripta Metall 24, (1990) pp. 241-244.

[8] Hsu Yung-Fu, Wang Wen Hsing and Wayman C. M., Metall Trans 22A (1991) pp. 1473-1478.

[9] Guilemany J. and Fernandez J., Scripta Metall 30 (1994) pp. 59-61.

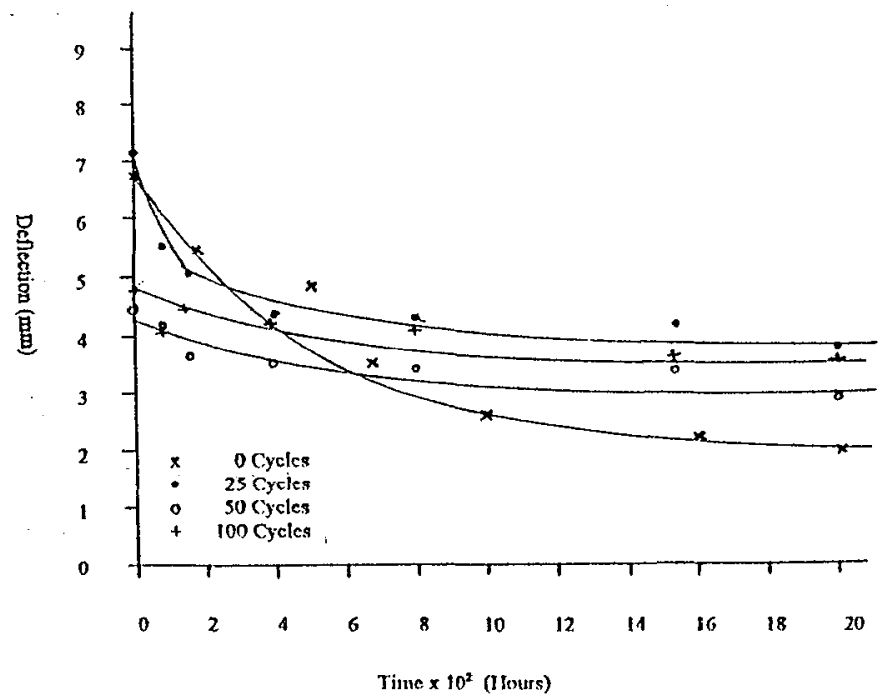

Figure 1. Ageing curves for NiTi alloy. 


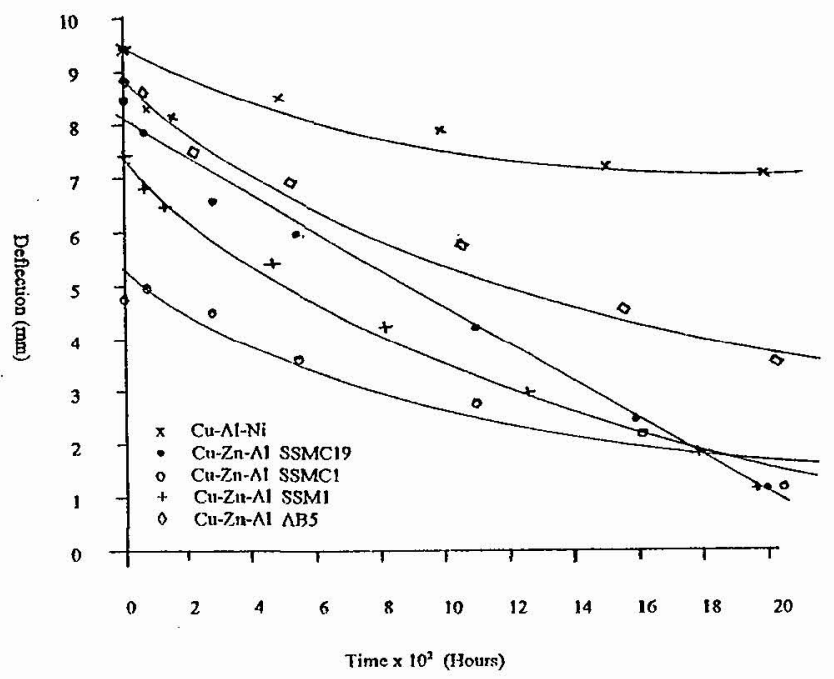

Figure 2. Ageing curves for copper-based alloys

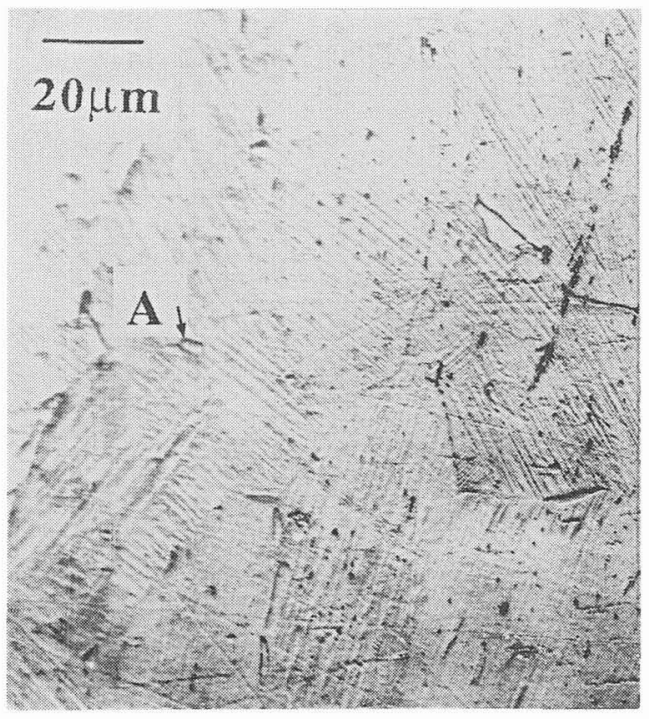

Figure 3. Duplex structure $\alpha \beta$ in sample AB5

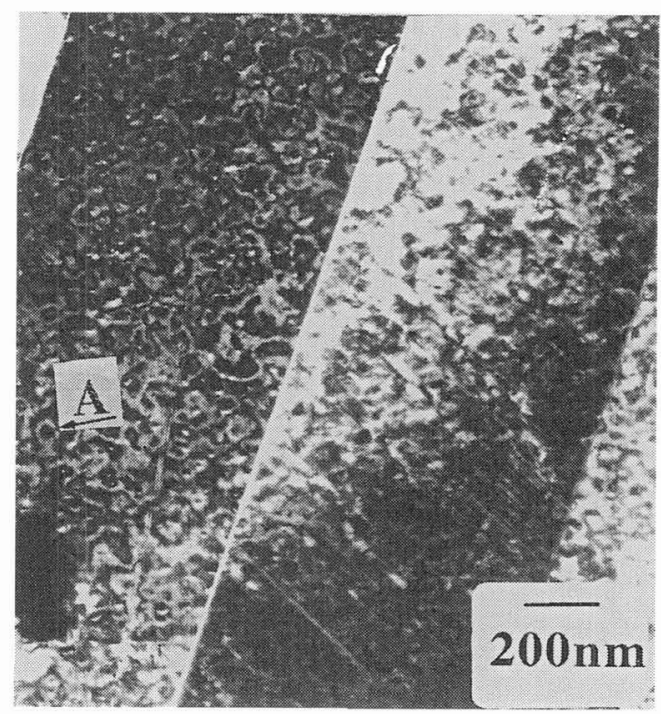

Figure 4. $\gamma$ Phase (marked A) in sample SSM1 